\title{
Attachment and Proliferation of Human-Adipose-Tissue-Derived Stem Cells on Bioactive Glass/PVA Hybrid Scaffolds
}

\author{
Viviane Gomide, ${ }^{1}$ Alessandra Arcoverde Cavalcanti Zonari, ${ }^{2}$ Natalia Martins Breyner, ${ }^{2}$ \\ Alfredo Miranda de Goes, ${ }^{2}$ and Marivalda M. Pereira ${ }^{1}$ \\ ${ }^{1}$ Department of Metallurgical and Materials Engineering, Federal University of Minas Gerais, \\ 30160-030 Belo Horizonte, MG, Brazil \\ ${ }^{2}$ Department of Biochemistry and Immunology, ICB, Federal University of Minas Gerais, \\ 31270-901 Belo Horizonte, MG, Brazil
}

Correspondence should be addressed to Viviane Gomide, vsgomide@gmail.com

Received 30 June 2011; Accepted 10 August 2011

Academic Editors: F. Ein-Mozaffari and D. Ricinschi

Copyright ( $\odot 2011$ Viviane Gomide et al. This is an open access article distributed under the Creative Commons Attribution License, which permits unrestricted use, distribution, and reproduction in any medium, provided the original work is properly cited.

\begin{abstract}
Bioactive glass/polymer hybrids are promising materials for biomedical applications because they combine the bioactivity of bioceramics with the flexibility of polymers. These advantages may be used in porous scaffolds for tissue-engineering applications. In previous works, hybrid foams bioactive glass/polyvinyl alcohol (PVA) were prepared by the sol-gel process. The hybrid foam $50 \%$ PVA $/ 50 \%$ bioactive glass was chosen in the composition range studied as the scaffold with better compromise in terms of pore structure and mechanical behavior. The aim of the present study was to evaluate the adhesion, viability, and growth behavior of human-adipose-tissue-derived stem cells on bioactive glass/PVA foams in vitro and their potential as scaffold for application in bone-tissue engineering. The pore structure of the hybrid samples used in the study was analyzed by microcomputed tomography, showing a modal pore diameter of $284 \mu \mathrm{m}$ and modal interconnect diameter of $138 \mu \mathrm{m}$. We found that cells are capable of adhesion, proliferation, growth, and ECM production on the scaffolds tested. The results show that the hybrid bioactive glass/PVA is a promising material for bone repair, providing a good environment for the adhesion and proliferation of human-adipose-tissuederived stem cells in vitro.
\end{abstract}

\section{Introduction}

The ultimate goal of tissue engineering is to replace, repair, or enhance the biological function of damaged, absent, or dysfunctional elements of a tissue. Bone regeneration has been a major goal of tissue engineering research. A promising approach combines different strategies that may use scaffold materials together with cells and growth factors. In this way, it is possible to construct a hybrid material that can repair a bone defect. For this strategy to be successful, materials with adequate properties need to be generated, and at the same time enhance cell adhesion, proliferation, and differentiation [1]. Some biodegradable polymers seem to be the ideal materials. These can be derived from natural (starch, chitosan, alginate, and silk) or synthetic polymers such as poly(hydroxyl ester), hydrogels, or thermoplastic elastomers [2]. Other important categories of materials are bioactive ceramics such as calcium phosphate and bioactive glasses or glass ceramics $[3,4]$. Today, composites of polymers and ceramics are being developed with the aim to increase the mechanical scaffold stability and to improve tissue interaction [5]. To fulfill as many requirements as possible, the advantage of the combination of polymers and ceramics seems to be a promising choice for bone-tissue engineering. A further requirement for a scaffold particularly in bone tissue engineering is a controllable interconnected porosity to direct the cells to grow into the desired physical form and to support vascularization of the ingrowth tissue [6]. In scaffold design, it is imperative to be able to quantify the pore sizes, and more importantly, the interconnections between 
the pores. X-ray microcomputed tomography $(\mu \mathrm{CT})$ has become a popular tool for obtaining 3D images of scaffold biomaterials [7].

Research focused on tissue regeneration by means of using mesenchymal stem cells (MSCs) is increasingly attracting a great deal of attention. Recently, MSCs were isolated from human liposuction fat aspirate and showed to have characteristics similar to bone-marrow-derived mesenchymal stem cell [8]. These cells, isolated from the stromal fraction of adipose tissue and named adipose-derived stem cells (ADSCs), are some of the most promising candidate cells for tissue engineering since it's an abundantly and available source and can be harvested with minimal morbidity. Furthermore, these cells have the ability to differentiate into various lineages under specific culture conditions [9].

In previous works, hybrid foams bioactive glass/polyvinyl alcohol (PVA) were prepared by the sol-gel process [10]. The hybrid foam $50 \%$ PVA $/ 50 \%$ bioactive glass was chosen in the composition range studied as the scaffold with better compromise in terms of pore structure and mechanical behavior. In this study, the pore structure of this hybrid was evaluated by $\mu \mathrm{CT}$, in order to access the pore and interconnect size distribution. Besides, the potential of these bioactive glass/PVA scaffolds for bone tissue engineering was evaluated by investigating the adhesion, viability, and growth behavior of human-adipose-tissue-derived stem cells.

\section{Materials and Methods}

2.1. Hybrid Synthesis. The reagents used to synthesize the hydrides were tetraethyl orthosilicate (TEOS) $98 \%$ by Across Organics, hydrochloric acid $(\mathrm{HCl}) 1 \mathrm{~mol} / \mathrm{L}$ by Merck, calcium chloride $\left(\mathrm{CaCl}_{2} \cdot 2 \mathrm{H}_{2} \mathrm{O}\right)$ by Vetec, poly(vinyl alcohol) (PVA) $80 \%$ hydrolyzed by Sigma-Aldrich, the surfactant sodium lauryl ether sulfate $27 \%$ by Sulfal and, hydrofluoric acid (HF) $48 \%$ by Merck. The hybrids were prepared by a sol-gel method described in a previous work with inorganic phase composition of $70 \mathrm{wt} \% \mathrm{SiO}_{2}-30 \mathrm{wt} \% \mathrm{CaO}$ and $\mathrm{PVA}$ fractions of $50 \mathrm{wt} \%$ [11]. The sol was prepared by acid hydrolysis of tetraethyl orthosilicate and addition of $\mathrm{CaCl}_{2}$. Adequate amounts of PVA solution (20 wt \%), sodium lauryl ether sulfate surfactant, and hydrofluoric acid solution were added to an aliquot of the sol. The mixture was then vigorously stirred to form the foam, which was next cast in a container where it gelled and was dried. Hybrid samples were immersed three times, 30 minutes each, in alcoholic calcium acetate solution. After neutralization, the hybrids were dried again at $40^{\circ} \mathrm{C}$ in an air-circulation oven for one week and, then, under high vacuum for 48 hours.

2.2. Scanning Electron Microscopy. The scaffolds were analyzed at the Department of Metallurgical and Materials Engineering, Federal University of Minas Gerais. The matrices were covered with gold (Sputter Coater-SPI Supplies) for $90 \mathrm{sec}$., at $13 \mathrm{~mA}$. The images were obtained by means of scanning electron microscope (JEOL $6360 \mathrm{LV}$ ), at $15 \mathrm{kV}$ and $750 \mathrm{~mA}$, to qualitatively assess the pore interconnectivity and size.
2.3. Micro-CT Analysis. The need to observe the pore structure, aggregates, pore topology, and geometry as well as the interconnectivity, has brought the development of tomography to the micrometric scale [12]. The knowledge of the porous structure of materials is fundamental to calculate the microstructural parameters, such as pore size distribution and their interconnectivity $[7,13]$. The structural analysis of the cylindrical samples ( $4 \mathrm{~mm}$ diameter) was performed on a 3D microtomographer (Phoenix X-Ray Systems and Services $\mathrm{GmbH}$ ), with a $7 \mathrm{~mm}$ voxel resolution. The 3D image analysis involved the $\mu \mathrm{CT}$ image conversion from the gray-scale images, according to the proper development and use of mathematical operators, which have been developed to verify the sample morphology.

2.4. Cell Origin, Isolation, and Culturing of hADSC. Human adipose tissue was obtained with informed consent from healthy patients who had liposuction surgery for esthetic reasons in the "Plastic Surgery Center-Dr. Luiz Alberto Lamana"-Belo Horizonte, Minas Gerais, Brazil. This project was approved by the Ethics Committee of the Federal University of Minas Gerais. No diabetes, hepatitis, metabolic diseases, or other systemic complications were reported for these donors. Isolation and culturing of adipose-tissuederived stem cell (hADSC) were performed as described by Zuk et al., 2001 [8]. To isolate hADSC, adipose tissues were washed with phosphate-buffered saline (PBS), and the extracellular matrix was digested with $0.075 \%$ type I collagenase for 2 hours to release the cellular fraction tissues and then centrifuged at $1,200 \mathrm{~g}$ for $10 \mathrm{~min}$ to obtain a pellet. The pellet was incubated for 2 days at $37^{\circ} \mathrm{C} / 5 \%$ $\mathrm{CO}_{2}$ in a culture medium (DMEM supplemented with $10 \% \mathrm{FBS}, 100 \mathrm{U} / \mathrm{mL}$ penicillin, and $100 \mathrm{U} / \mathrm{mL}$ streptomycin). Following incubation, the tissue culture plates were washed to remove residual nonadherent cells and maintained at $37^{\circ} \mathrm{C}$ $15 \% \mathrm{CO}_{2}$ in the control medium. The stromal cells were then cultured for 7 to 10 days until they reached confluence. The cells were then harvested by digestion with $0.05 \%$ trypsinEDTA, centrifuged at $1200 \mathrm{~g}$ for 5 minutes, suspended in culture medium, and plated at a density of approximately $2 \times 10^{4}$ cells $/ \mathrm{cm}^{2}$. Cells were cultured to confluence before a second harvesting and replating procedure as described above. The final hADSC used were taken at the 4th passage.

2.5. Phenotypic Characterization of hADSC. The phenotypic characterization was performed by Flow Cytometric Analyses. The adherent cells were harvested with $0.05 \%$ trypsinEDTA. For the analyses of hADSC, aliquots containing $5 \times 10^{5}$ cells were incubated with monoclonal primary antibodies specific for CD29, CD44, CD45, and CD73 (Abcam) for $30 \mathrm{~min}$ at $4^{\circ} \mathrm{C}$. Both types of cells were washed and incubated with secondary antibody, IgG anti-mouse FITC conjugated (Invitrogen) for an additional $30 \mathrm{~min}$ at $4^{\circ} \mathrm{C}$. As control, cells were stained with isotype IgG anti mouse FITC conjugated. Finally, the cells were fixed in 10\% formalin and analyzed using a FACScan argon laser cytometer (Becton Dickson, San Jose, CA). For each sample, 15000 events were acquired and analyzed using Cell Quest software. Cell surface marker 


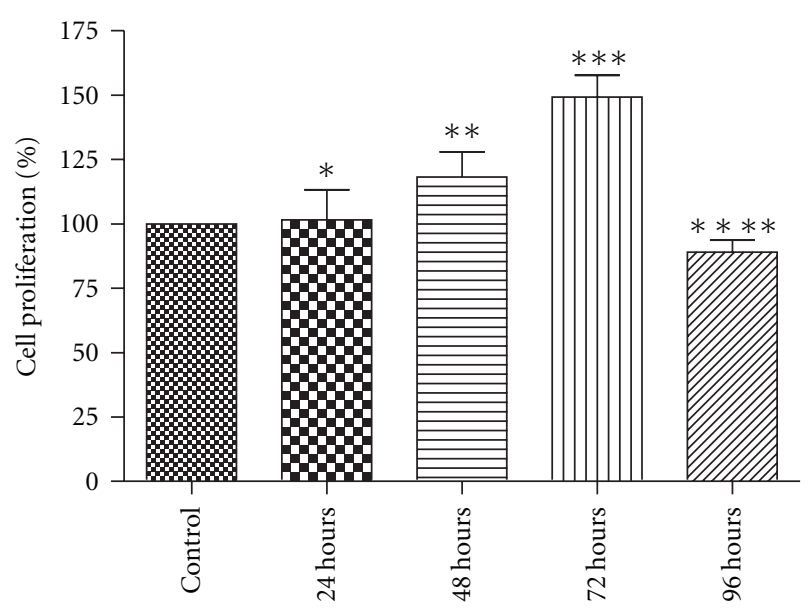

FIGURE 1: Cell viability as a function of culture time, measured by MTT assay.

expression was determined by comparison with isotype control on a histogram.

2.6. Cellular Viability. For the experiments, confluent cells from the 4th passage were used. For the cell culture studies, hybrid foams were cut, sterilized under Gamma Rays, and soaked in the culture medium for 24 hours before testing. hADSC were plated and, after adhesion, the foam samples were gently deposited over the cells. The density used was $5 \times 10^{5}$ cells $/ \mathrm{mL}$. The culture medium DMEM was changed in intervals of 48 hours. After $72 \mathrm{~h}$ of incubation, hADSC viability was evaluated by MTT (3) 4,5 dimethylthiazoleyl) 2,5 diphenyl-tetrazolium bromide assay, based on the reduction of tetrazolium salt into formazan crystals by dehydrogenase, present in living cells mitochondria. The time of 72 hours was chosen because cells presented appropriate morphology and higher cell viability for this culture period, as assessed by MTT assay (Figure 1). $200 \mu \mathrm{L}$ of culture medium was left in each well and $170 \mu \mathrm{L}$ of stock solution of MTT was added $(5 \mathrm{mg} / \mathrm{mL})$. Two hours later, the cell morphology was analyzed by inverted optical microscopy and formazan salts were solubilized with $200 \mu \mathrm{L}$ of SDS $10 \% \mathrm{HCl}$. After incubation, for 18 hours in a controlled $5 \%$ $\mathrm{CO}_{2}, 95 \%$ humidified incubator at $37^{\circ} \mathrm{C}$, the optical density measurement was performed at $595 \mathrm{~nm}$.

2.7. Alkaline Phosphatase Activity. The alkaline phosphatase production was evaluated after $72 \mathrm{~h}$ of incubation of the cells (hADSC) by a BCIP-NBT (Gibco (Burlington-Ontario, Canada) assay. This assay is based on a chromogenic reaction initiated by the cleavage of the phosphate group of BCIP (5-bromo-4-cloro-3-indolilfosfate p-toluidine) by alkaline phosphatase present in the cells. This reaction produces a proton which reduces NBT (Nitroblue tetrazolium cloridric) to an insoluble purple precipitate. Briefly, the supernatant of each well was removed and the cell layer was rinsed twice with PBS. Then, $200 \mu \mathrm{L}$ of BCIP-NBT solution, prepared according to the manufacturer's protocol, was added to each well. After $2 \mathrm{~h}$ of incubation, the cells were observed by optical microscopy and the insoluble purple precipitates were solubilized with $210 \mu \mathrm{L}$ of SDS $10 \% \mathrm{HCl}$ and incubated for $18 \mathrm{~h}$. The optical density measurement was performed at $595 \mathrm{~nm}[14]$.

2.8. Collagen Production. The hADSC collagen production was analyzed by SIRCOL assay in the culture supernatant SIRCOL kit: Biocolor (Newtonabbey, N Ireland) and evaluated after $72 \mathrm{~h}$ of incubating these cells (hADSC). These methods are based on the selective binding property of the Sirius-red dye to the (Gly-X-Y) tripeptide end sequence of mammalian collagen. The solubilized collagen was measured by an optical density analysis at $595 \mathrm{~nm}$. The amount of collagen was calculated based on a linear regression from previously known concentrations of type I collagen and their optical density measurement [14].

2.9. Statistical Analysis. All data were presented as average \pm standard deviation (SD). To test the significance of the observed differences between the study groups, a statistical evaluation was carried out using a one-way ANOVA. A value of $P<0.05$ was considered to be statistically significant.

\section{Results and Discussion}

An important feature of materials derived from a sol-gel process is the high porosity obtained after drying. Consequently, a large range of physical properties and microstructural control can be reached for same composition materials, by means of varying the volumetric fraction, the pore structure distribution, and connectivity. The porosity of the generated foams was determined by means of two techniques: scanning electron microscopy (SEM), which aimed to qualitatively analyze the pore size and interconnectivity, and computerized X-ray microtomography $(\mu \mathrm{CT})$. The SEM analyses showed that the produced hybrid foams presented pore size from $60-400 \mu \mathrm{m}$ and a qualitative observation indicated an interconnected pore structure (Figure 2(a)). The 3D image of the scaffold under study, obtained by $\mu \mathrm{CT}$, clearly shows the pore structure and interconnectivity (Figure 2(b)). The pore size and interconnected-size distributions obtained using this technique are presented in Figure 3. The hybrid material presented a large pore size range, varying from 80 to $500 \mu \mathrm{m}$, with larger volume fraction in the range 200 to $400 \mu \mathrm{m}$. It was noticed also a large distribution of interconnect equivalent diameter, ranging from 35 to $450 \mu \mathrm{m}$, but with a higher area fraction of interconnects around $100 \mu \mathrm{m}$. From these distributions, the modal pore diameter determined is $284.2 \mu \mathrm{m}$, and the modal interconnect diameter is $137.6 \mu \mathrm{m}$. The results regarding porosity and interconnectivity are similar to the two employed methodologies, SEM or $\mu \mathrm{CT}$. In order to start the formation process of a bone tissue precursor inside the scaffold, the interconnected pore net must necessarily be of diameters larger than $100 \mu \mathrm{m}$ [15]. It is acceptable to say that in terms of pore structure the hybrids seem to be adequate for bone tissue engineering, since they have a highly porous, interconnected net, with sizes enough for cell migration, fluid and tissue exchange, and, eventually, angiogenesis. 


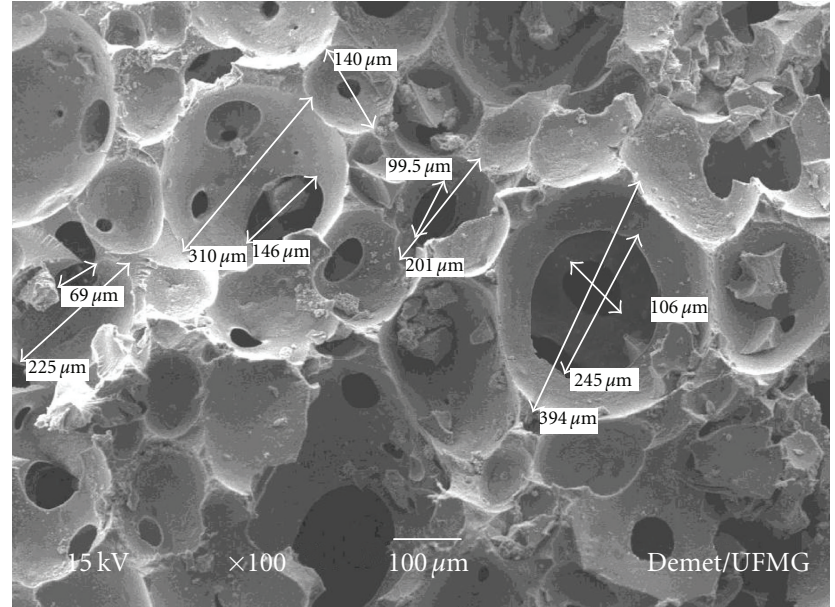

(a)

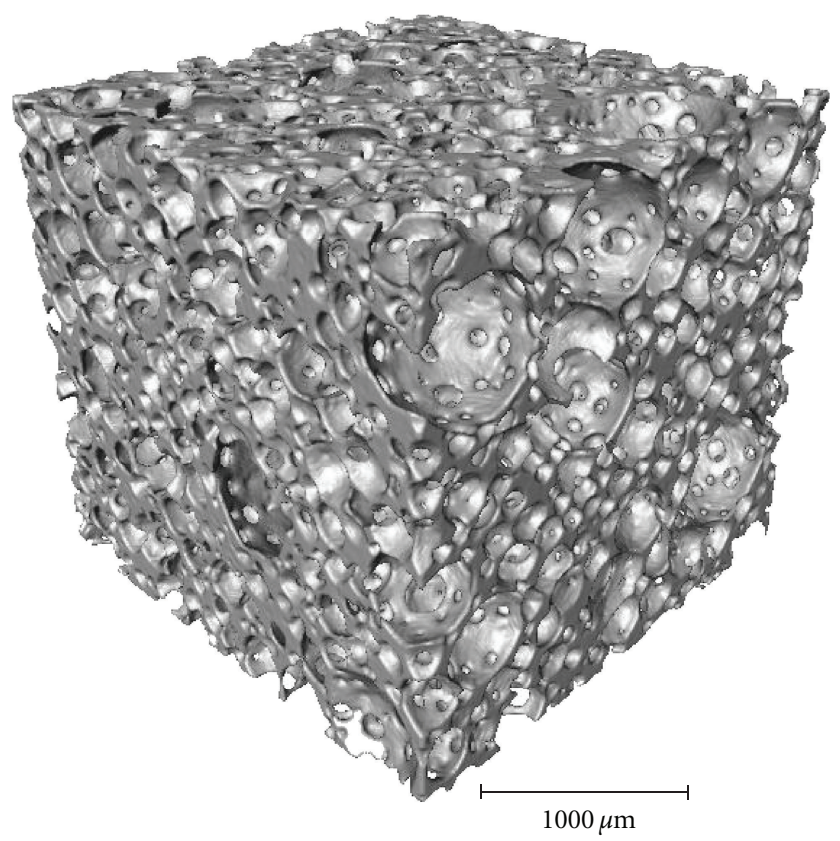

(b)

FIGURE 2: SEM micrograph of hybrid scaffold with pore size indication (a) and tridimensional image of the scaffold obtained by micro computed tomography (b).

Bioactive glass/PVA scaffolds were produced, showing a structure of interconnected pores, similar to that of trabecular bone. The difference between the structures is that the scaffold pores showed to be more in a spherical shape. According to literature, the trabecular bone presents irregular pore shapes and sizes [7]. The scaffolds presented spherical pores due to the process by which they had been obtained. The production of foams from the sol-gel process occurs by adding a foaming agent in the gelling stage of the sol-gel process, and under vigorous agitation it is obtained an amount of foam, which will depend on the surfactant concentration on the agitation time and the viscosity of the solution. The amount of foam is directly associated with the porosity and pore size [11]. In this process, bubbles are

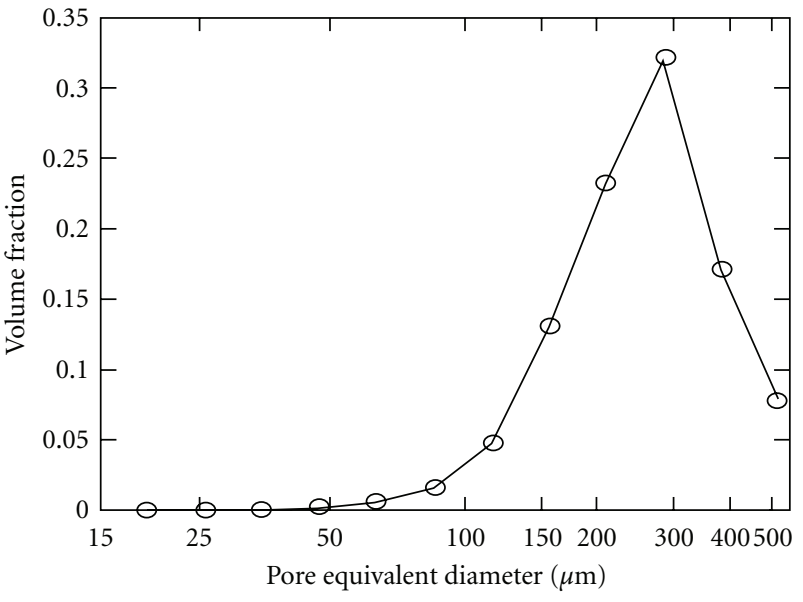

(a)

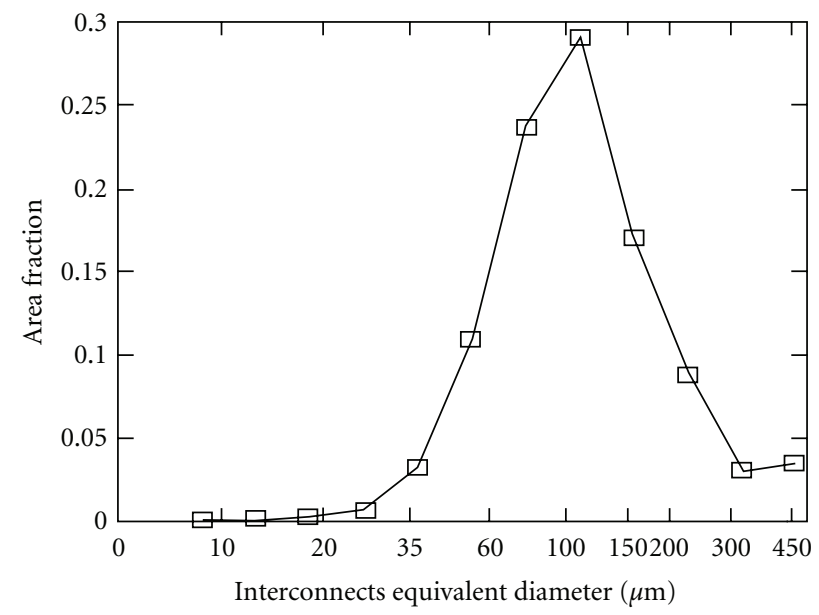

(b)

Figure 3: Pore size distribution (a) and interconnect size distribution (b) obtained by $\mu \mathrm{CT}$ analysis.

created in a liquid, when it is well-mixed with the surfactant. The role of the surfactant is to reduce the surface tension of the sol and stabilize the air bubbles, before the gelling process. The interconnectivity occurs due to the fact that spherical air bubbles touch each other immediately before gelling and are separated only by a thin sol membrane. After gelling and subsequent thermal processes, the resulting water is drained and the width of the wall decreases; a thin membrane is formed, leaving interconnections [7].

This study has examined mesenchymal stem cells derived from human adipose tissue in the presence of scaffolds made out of a bioactive glass containing hybrid. These cells displayed a fibroblastic morphology and were plastic adherent. Also, they were able to self-renew and to form colonies (Figure 4(a)). Isolated human adipose tissue cells were expanded and characterized for specific surface antigen expression by flow cytometry analysis. After the 4th passage, the phenotypic characterization of the cell population showed that cells expressed CD29 (92\%), CD44 (94\%), and CD73 (94\%) (Figure 4(b)). This culture was completely isolated from lymphocytes and hematopoietic stem cells 


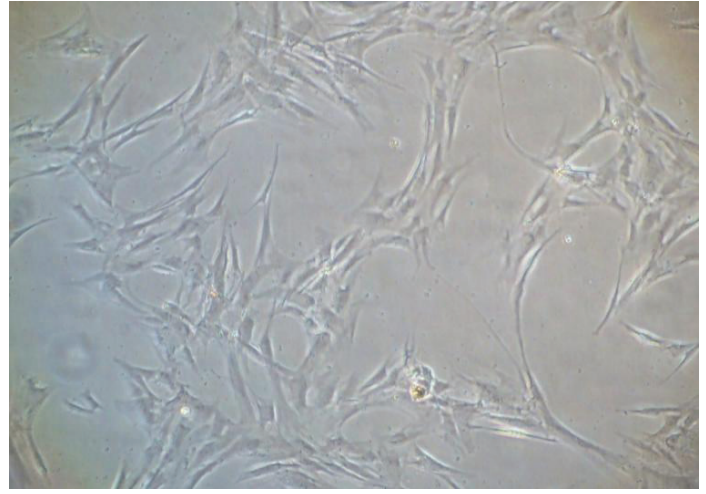

(a)

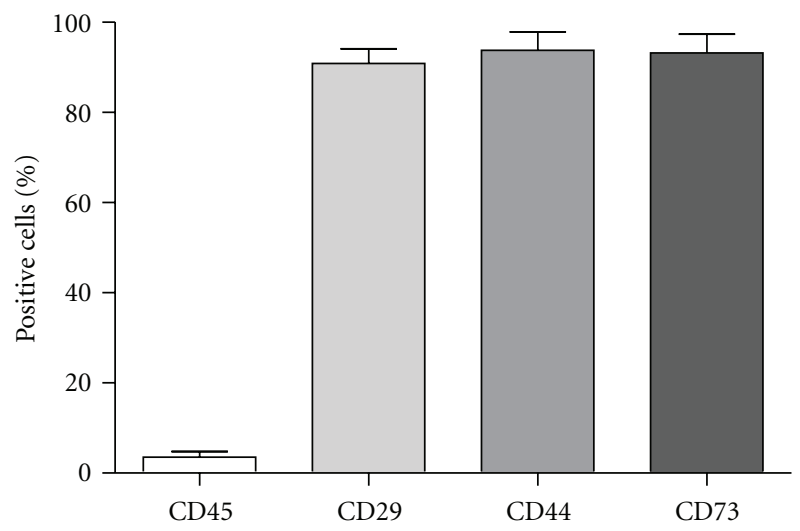

(b)

Figure 4: Cell morphology of hADSC at 4th passage (a) and phenotypic characterization of hADSC at 4 th passage (b).

since the cells did not express CD45 (less than 5\%). This expression pattern is characteristic of mesenchymal stem cells, ensuring us that the population that we are working with is composed in the majority with this cell type $[8,16]$.

In the tissue engineering field, there has been a special interest in seeding MSCs into porous scaffolds, which provides a possible approach for the reconstruction of tissue defects [17]. Figure 5 shows hADSC adhered inside the pores of the hybrid scaffold, showing that we have synthesized a composite that demonstrated the capability of cellular attachment and proliferation from the initial seeding as well as into the internal pore structure.

In order to investigate the viability and proliferation of hADSC, in the presence of the hybrid, a study of the MTT metabolism was performed. The MTT is employed to evaluate the material cytotoxicity in tissue engineering, and optical density can provide an indication of cell growth and proliferation in several materials. $100 \%$ of the optical density was considered for cell cultures without the hybrid. The MTT tests showed that hADSC proliferated in the presence of the scaffold, which indicated that the bioactive glass had no negative effect on the viability and proliferation of hADSC (Figure 6). This can be attributed to both the porosity of the scaffold and the presence of a bioactive glass phase in the hybrid material. Valerio and collaborators showed that the ionic product of bioactive glass containing $60 \%$ silica

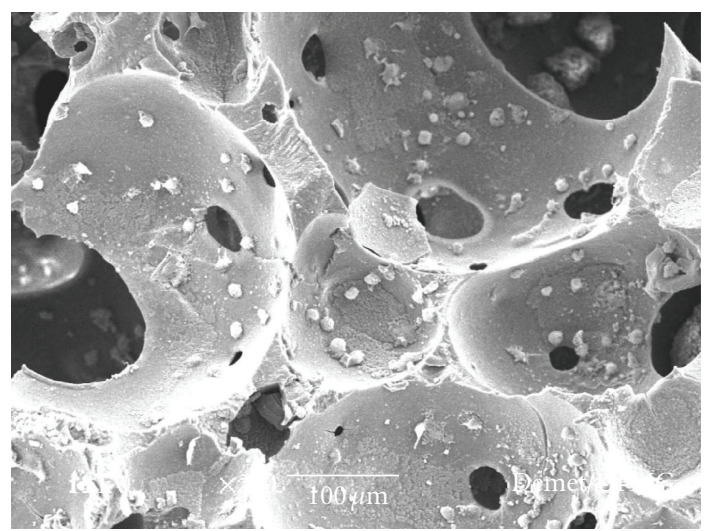

FIGURE 5: hADSC cells adhered inside the pores of the hybrid scaffold.

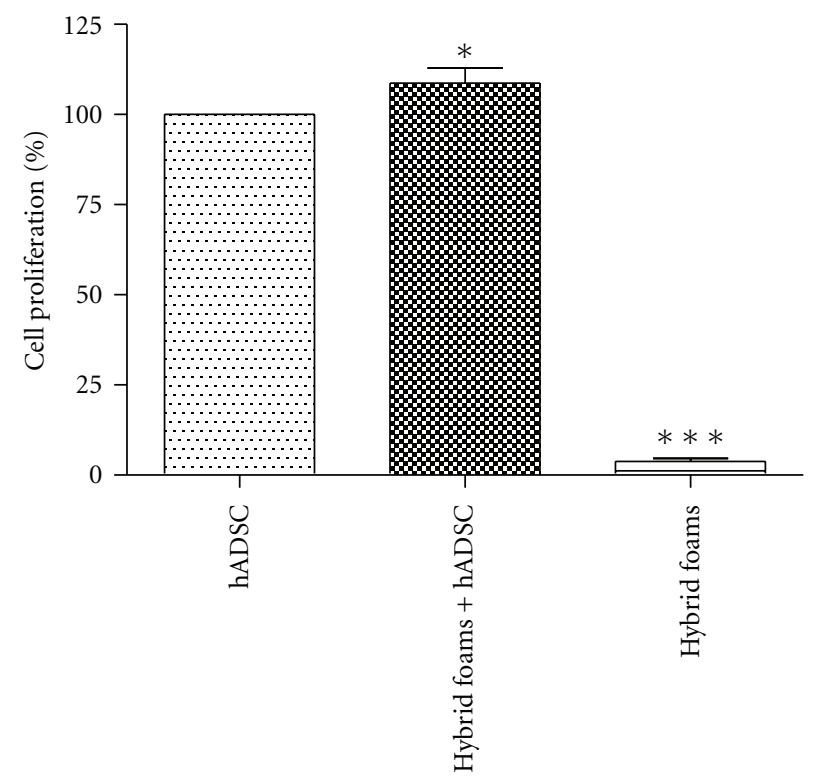

FIgURE 6: Cell viability evaluated by MTT assay in \% of hADSC cells in the presence of hybrid scaffolds after 72 hours in the cell culture. Results represent mean \pm SD of triplicates from the experiment. $* P<0.05$ compared to controls.

promotes proliferation of osteoblasts [14]. Similar results were verified by Jell et al. which analyzed the effect of 45S5 Bioglass on fetal osteoblast (FOB) [18]. Jones and collaborators also observed the same behavior when used a bioactive glass foam with composition $70 \mathrm{~mol} \% \mathrm{SiO}_{2}, 30 \mathrm{~mol} \% \mathrm{CaO}$ on primary human osteoblast (HOB) cells [19].

The production of alkaline phosphatase activity was lower in the presence of the hybrid compared with the control group (Figure 7). The evaluation of alkaline phosphatase activity is a common marker of bone cell differentiation. Several studies have suggested that alkaline phosphatase activity is enhanced when cells are grown on bioactive glass with different types of cells, like human osteoblasts [20] and rat MSC [21-23]. A hypothesis for increased bone formation around bioactive glass implants is that either the attachment 


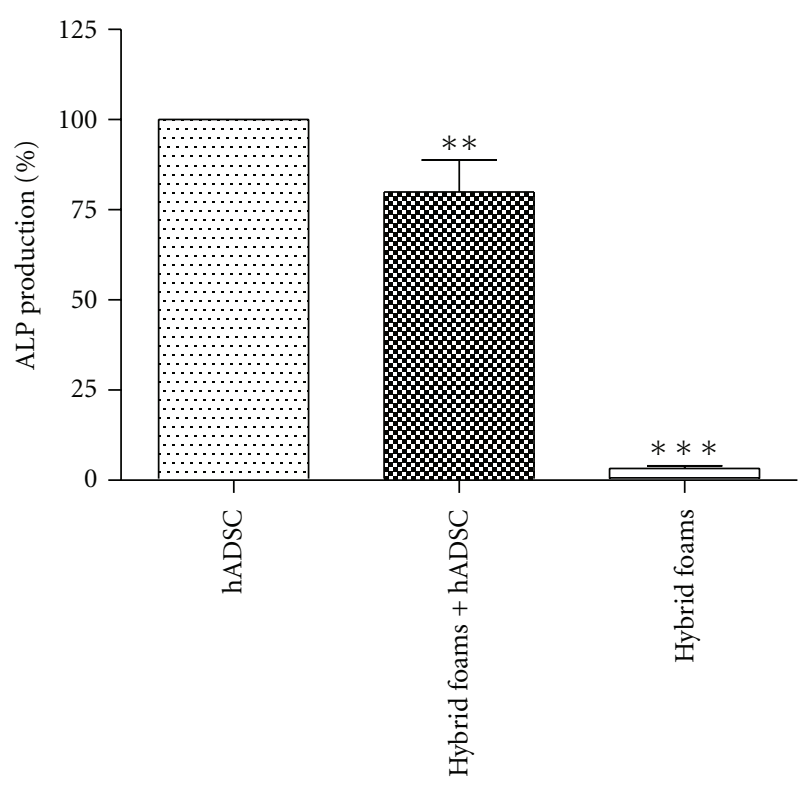

Figure 7: Production of alkaline phosphatase (ALP) in \%, compared with control set, which represents $100 \%$ viable cells after 72 hours in the cell culture. Results represent mean \pm SD of triplicates from the experiment. ${ }^{*} P<0.05$ compared to controls.

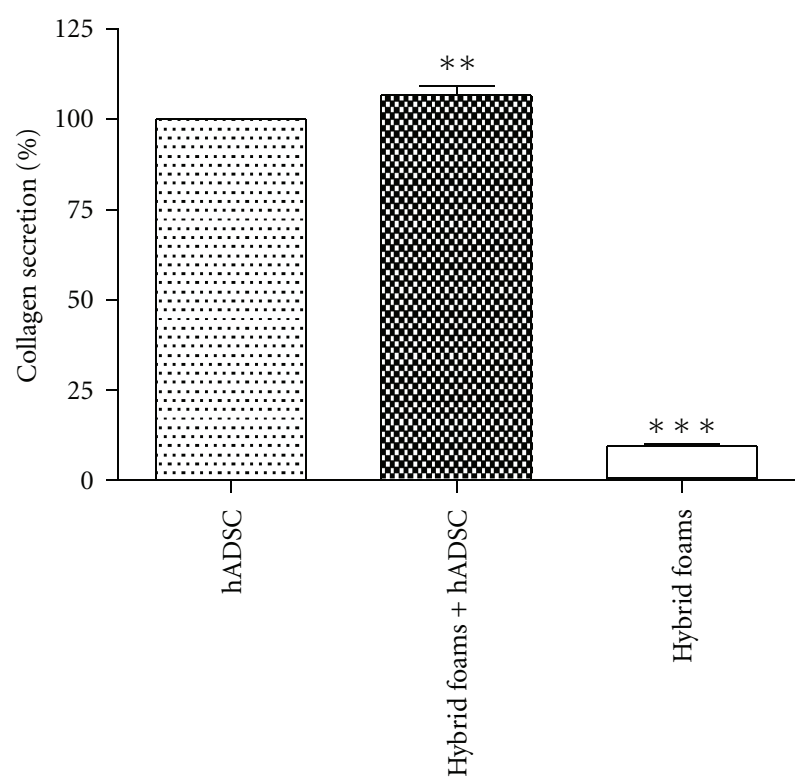

FIGURE 8: Total collagen production in \%, compared with control set, which represents $100 \%$ viable cells after 72 hours in the cell culture. Results represent mean \pm SD of triplicates from the experiment. ${ }^{*} P<0.05$ compared to controls.

to the bioactive glass or exposure to its dissolution products enhances osteoblastic differentiation from osteogenic precursors which arise from MSC. In this study, we did not promote osteoblastic differentiation; it was just an initial evaluation of the behavior of undifferentiated stem cells in the presence of the hybrid material. Unlike what has already been reported, the culture of hADSC in the presence of the bioactive glass showed no consistent increase in alkaline phosphatase activity over controls without bioactive glass exposure. Reilly et al. (2007) [24] showed that human MSC derived from bone marrow in the presence of 45S5 bioactive glass also did not increase alkaline phosphatase activity.

The secretion of collagen was larger in hADSC in the presence of the hybrid, when compared to the control group (Figure 8). This result shows that cells are able to produce an extracellular matrix, in the presence of the hybrid.

\section{Conclusions}

In this study, we found that cells are capable of adhesion, proliferation, growth, and extracellular matrix production on the hybrid scaffolds studied. The results anticipate that the hybrid scaffold made out with polymer PVA and bioactive glass will be an adequate scaffold in combination with stem cell seeding in osteogenic differentiation.

\section{Acknowledgments}

The authors thank CNPq, CAPES, and FAPEMIG for financial support. The authors would like to express their gratitude to Dr. Julian R. Jones (Imperial College London, UK) for the $\mu \mathrm{CT}$ analysis.

\section{References}

[1] G. A. Silva, O. P. Coutinho, P. Ducheyne, I. M. Shapiro, and R. L. Reis, "The effect of starch and starch-bioactive glass composite microparticles on the adhesion and expression of the osteoblastic phenotype of a bone cell line," Biomaterials, vol. 28, no. 2, pp. 326-334, 2007.

[2] A. M. Martins, M. I. Santos, H. S. Azevedo, P. B. Malafaya, and R. L. Reis, "Natural origin scaffolds with in situ pore forming capability for bone tissue engineering applications," Acta Biomaterialia, vol. 4, no. 6, pp. 1637-1645, 2008.

[3] G. Sandeep, H. K. Varma, T. V. Kumary, S. S. Babu, and A. John, "Characterization of novel bioactive glass coated hydroxyapatite granules in correlation with in vitro and in vivo studies," Trends in Biomaterials and Artificial Organs, vol. 19, no. 2, pp. 99-107, 2006.

[4] J. F. Mano, R. A. Sousa, L. F. Boesel, N. M. Neves, and R. L. Reis, "Bioinert, biodegradable and injectable polymeric matrix composites for hard tissue replacement: state of the art and recent developments," Composites Science and Technology, vol. 64, no. 6, pp. 789-817, 2004.

[5] K. Rezwan, Q. Z. Chen, J. J. Blaker, and A. R. Boccaccini, "Biodegradable and bioactive porous polymer/inorganic composite scaffolds for bone tissue engineering," Biomaterials, vol. 27, no. 18, pp. 3413-3431, 2006.

[6] A. J. Salgado, O. P. Coutinho, and R. L. Reis, "Bone tissue engineering: state of the art and future trends," Macromolecular Bioscience, vol. 4, no. 8, pp. 743-765, 2004.

[7] J. R. Jones, R. C. Atwood, G. Poologasundarampillai, S. Yue, and P. D. Lee, "Quantifying the 3D macrostructure of tissue scaffolds," Journal of Materials Science: Materials in Medicine, vol. 20, no. 2, pp. 463-471, 2009.

[8] P. A. Zuk, M. Zhu, H. Mizuno et al., "Multilineage cells from human adipose tissue: implications for cell-based therapies," Tissue Engineering, vol. 7, pp. 211-228, 2001. 
[9] H. Mizuno, "Adipose-derived stem cells for tissue repair and regeneration: ten years of research and a literature review," Journal of Nippon Medical School, vol. 76, no. 2, pp. 56-66, 2009.

[10] H. S. Costa, A. A. P. Mansur, E. F. Barbosa-Stancioli, M. M. Pereira, and H. S. Mansur, "Hybrid bloactive glass-polyvinyl alcohol prepared by sol-gel," Materials Science Forum, vol. 687, pp. 62-66, 2008.

[11] M. De Barros Coelho and M. Magalhães Pereira, "Sol-gel synthesis of bioactive glass scaffolds for tissue engineering: effect of surfactant type and concentration," Journal of Biomedical Materials Research-Part B Applied Biomaterials, vol. 75, no. 2, pp. 451-456, 2005.

[12] A. Tedeschi, F. Auriemma, R. Ricciardi et al., "A study of the microstructural and diffusion properties of poly(vinyl alcohol) cryogels containing surfactant supramolecular aggregates," Journal of Physical Chemistry B, vol. 110, no. 46, pp. 23031-23040, 2006.

[13] F. Appolonio, M. C. Aragão, M. Furlan, P. B. Rapport, R. Yoshimura, and R. V. R. Zainni, "Síndrome de van der Hoeve e Kleyn: relato de caso," Acta Cirúrgica Brasileira, vol. 18, no. 4, pp. 11-18, 2003.

[14] P. Valerio, M. M. Pereira, A. M. Goes, and M. F. Leite, "The effect of ionic products from bioactive glass dissolution on osteoblast proliferation and collagen production," Biomaterials, vol. 25, no. 15, pp. 2941-2948, 2004.

[15] S. F. Hulbert and J. J. Klawille, "Tissue reaction to 3 ceramics of porous and non porous structures," Journal of Biomedical Materials Research, vol. 6, no. 5, p. 347, 1972.

[16] M. Dominici, K. Le Blanc, I. Mueller et al., "Minimal criteria for defining multipotent mesenchymal stromal cells. The International Society for Cellular Therapy position statement," Cytotherapy, vol. 8, no. 4, pp. 315-317, 2006.

[17] W. J. Li, R. Tuli, X. Huang, P. Laquerriere, and R. S. Tuan, "Multilineage differentiation of human mesenchymal stem cells in a three-dimensional nanofibrous scaffold," Biomaterials, vol. 26, no. 25, pp. 5158-5166, 2005.

[18] G. Jell, I. Notingher, O. Tsigkou et al., "Bioactive glass-induced osteoblast differentiation: a noninvasive spectroscopic study," Journal of Biomedical Materials Research-Part A, vol. 86, no. 1, pp. 31-40, 2008.

[19] J. R. Jones, O. Tsigkou, E. E. Coates, M. M. Stevens, J. M. Polak, and L. L. Hench, "Extracellular matrix formation and mineralization on a phosphate-free porous bioactive glass scaffold using primary human osteoblast (HOB) cells," Biomaterials, vol. 28, no. 9, pp. 1653-1663, 2007.

[20] M. Bosetti, L. Zanardi, L. Hench, and M. Cannas, "Type I collagen production by osteoblast-like cells cultured in contact with different bioactive glasses," Journal of Biomedical Materials Research A, vol. 64, no. 1, pp. 189-195, 2003.

[21] S. Radin, G. Reilly, G. Bhargave, P. S. Leboy, and P. Ducheyne, "Osteogenic effects of bioactive glass on bone marrow stromal cells," Journal of Biomedical Materials Research—Part A, vol. 73, no. 1, pp. 21-29, 2005.

[22] A. M. Osyczka and P. S. Leboy, "Bone morphogenetic protein regulation of early osteoblast genes in human marrow stromal cells is mediated by extracellular signal-regulated kinase and phosphatidylinositol 3-kinase signaling," Endocrinology, vol. 146, no. 8, pp. 3428-3437, 2005.

[23] M. Bosetti and M. Cannas, "The effect of bioactive glasses on bone marrow stromal cells differentiation," Biomaterials, vol. 26, no. 18, pp. 3873-3879, 2005.
[24] G. C. Reilly, S. Radin, A. T. Chen, and P. Ducheyne, "Differential alkaline phosphatase responses of rat and human bone marrow derived mesenchymal stem cells to $45 \mathrm{~S} 5$ bioactive glass," Biomaterials, vol. 28, no. 28, pp. 4091-4097, 2007. 

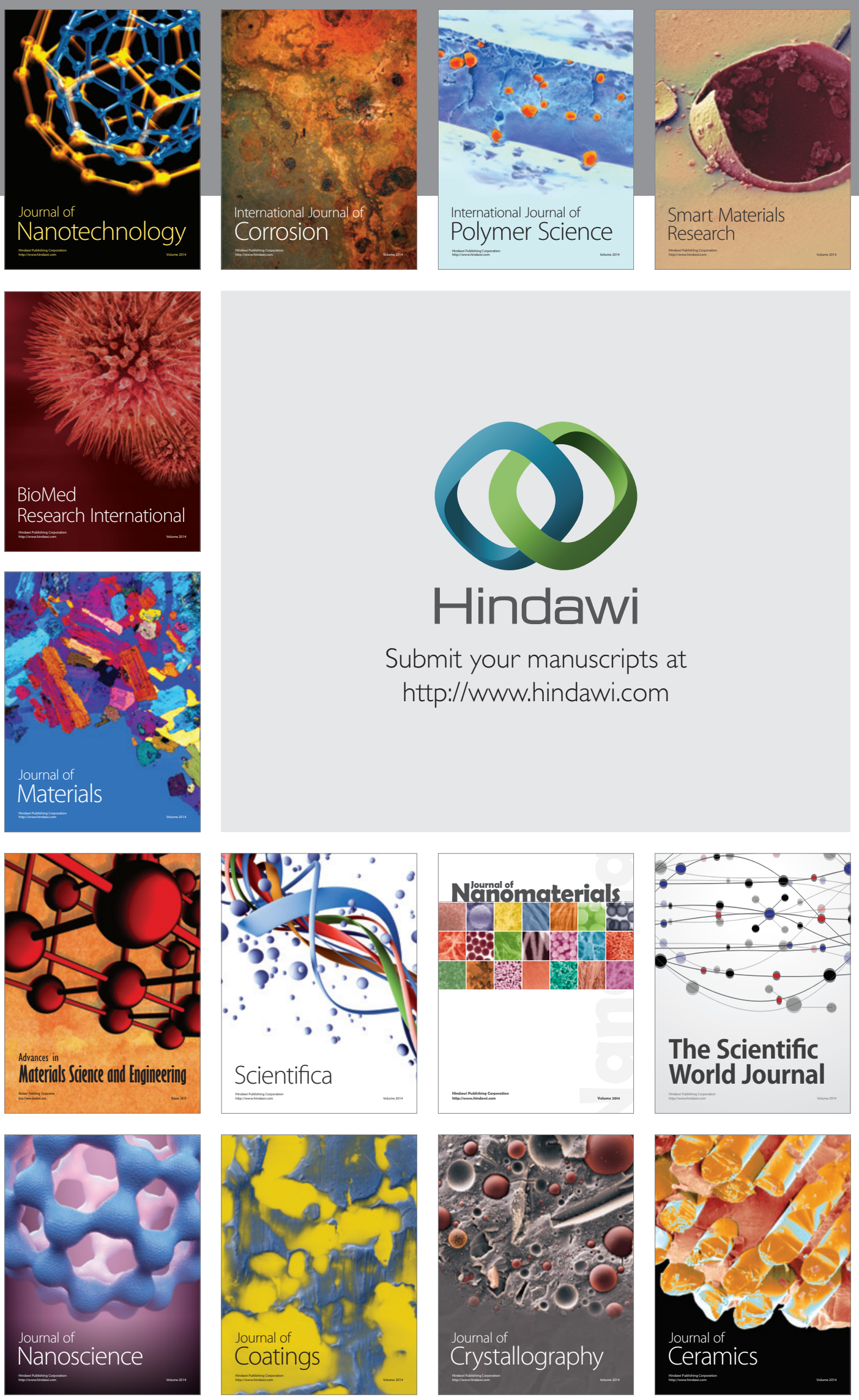

The Scientific World Journal

Submit your manuscripts at

http://www.hindawi.com

\section{World Journal}

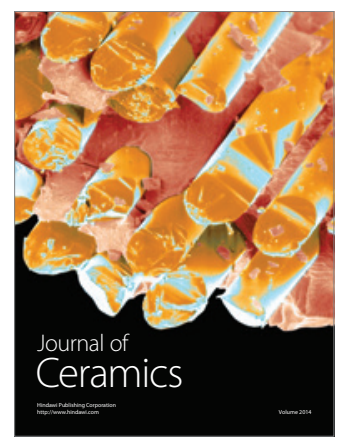

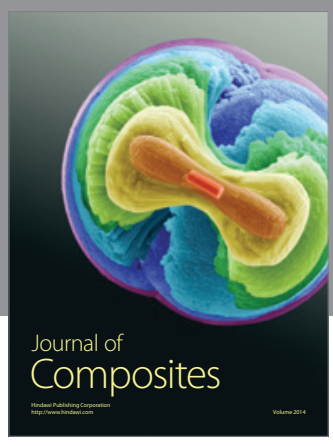
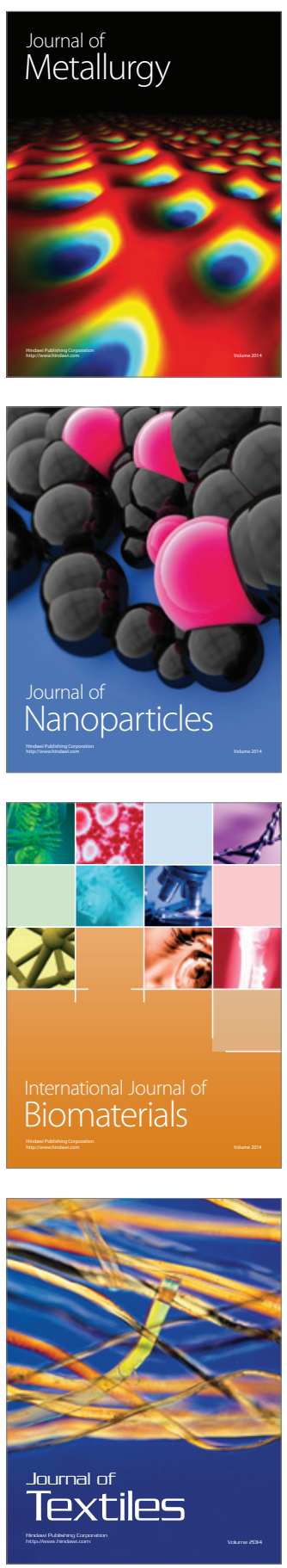